\title{
Parental opinions regarding an opt-out consent process for inpatient pediatric prospective observational research in the US
}

This article was published in the following Dove Press journal:

Pragmatic and Observational Research

19 January 2017

Number of times this article has been viewed

\author{
Danielle M Fernandes' \\ Allison P Roland ${ }^{2}$ \\ Marilyn C Morris ${ }^{3}$ \\ 'The Children's Hospital of New York, \\ ${ }^{2}$ Postbaccalaureate Prehealth Studies \\ Program, NYU College of Arts and \\ Science, ${ }^{3}$ Department of Pediatrics, \\ Columbia University Medical Center, \\ New York, NY, USA
}

Objective: To explore parental opinions regarding opt-out consent for inpatient pediatric prospective observational research in the US.

Study design: A series of handouts describing hypothetical observational research studies with opt-out consent were reviewed by parents of hospitalized children. A verbal survey explored parental opinions about the proposed consent process.

Results: A total of 166 parents reviewed the handout and completed the survey. Only 2/166 parents $(1.2 \%)$ objected to the study described and another $10(6.0 \%)$ cited concern about the privacy of their child's medical information. A total of 157 parents were asked "Is it okay to tell you about this kind of research using this handout?" - 116 (74\%) responded positively, 19 (12\%) responded negatively, and $21(13 \%)$ made an indeterminate or neutral response. When parents were asked to recommend a specific consent approach for observational research, $86(52 \%)$ chose an opt-in approach, 54 (33\%) chose opt-out, and 25 (15\%) chose "no consent needed". There were no significant associations between parental preferences and whether the child was admitted to the intensive care unit vs. pediatric ward, and no significant difference found based on type of handout reviewed (generic vs. study-specific).

Conclusion: Few parents voiced objection to a hypothetical opt-out consent process for inpatient pediatric prospective observational research. When asked to recommend a specific consent approach, though, approximately half chose an opt-in approach. These data suggest that an optout consent process for observational inpatient research is likely to be acceptable to parents, but assessment of an opt-out consent process in a real-world setting is needed.

Keywords: informed consent, minimal risk, research ethics

\section{Introduction}

Retrospective medical record research is routinely conducted with a waiver of the requirement for informed consent. Prospective observational research is similar to retrospective medical record research in that the research does not impact the subjects' clinical care and that the main risk to the subject is a breach of confidentiality. However, researchers conducting prospective observational research often may have an opportunity to seek consent from subjects or their surrogates.

In the US, the requirement for informed consent for research may be waived by the institutional review board (IRB) in select circumstances if the risk to the subject is minimal and the research could not practicably be carried out without the waiver. ${ }^{1}$ Retrospective chart reviews are commonly conducted with a waiver of the requirement for informed consent on this basis. The extent to which it is practicable to obtain informed
Deprespondence: Marilyn C Morris University Medical Center, 3959

Broadway CHN 10-24, New York, 10032 NY, USA

Tel +l 2 I 23058458

$\mathrm{Fax}+12123422217$

Email mcm2113@cumc.columbia.edu 
consent for prospective observational research, however, will vary from study to study. In some cases, a requirement for informed consent may introduce clinically meaningful selection bias in minimal risk research, threatening the validity of the study. ${ }^{2-6}$ The Secretary's Advisory Committee on Human Research Protections (SACHRP) supports waiving the requirement for informed consent when a requirement for informed consent would introduce meaningful bias and threaten the scientific validity of the study. ${ }^{7}$ Opt-out consent processes have been shown to lessen selection bias and to increase participation rates when compared to opt-in consent processes..$^{8-10}$

SACHRP recommends: "Once the IRB has determined that the waiver or alteration does not adversely impact the ethical nature or scientific rigor of the research, logistical issues (e.g. cost, convenience, and speed) may be considered". 7 This statement implicitly recognizes the cumbersome nature of seeking informed consent and empowers IRBs to consider alternative consent processes when, and only when, doing so would not infringe upon the rights or welfare of research subjects. An opt-out consent mechanism for prospective observational research may allow researchers to conduct important research that would be impracticable without a waiver, while preserving a parent's opportunity to determine whether s/he wants a child to participate in research.

When pediatric research is conducted using an opt-out consent process, parents of eligible subjects are informed about a study, and the child is enrolled unless the parent contacts the research team to refuse participation. Though published studies using an opt-out consent process indicate that a large majority of participants favor, or do not object to the opt-out processes, ${ }^{8-12}$ the use of opt-out consent mechanisms remains controversial. ${ }^{10,13}$

We are aware of no inpatient pediatric studies using an opt-out consent process. We conducted the present study to explore the extent to which parents support using opt-out consent for prospective, observational research involving hospitalized children. We also aimed to identify factors that could help optimize an opt-out consent process for prospective, observational research.

\section{Methods}

We developed a series of one-page handouts describing hypothetical prospective observational research using an opt-out consent process. English-speaking parents or legal guardians of hospitalized children ( $<18$ years old) were asked to read the handout and to participate in a short verbal survey eliciting their opinions about consent for prospective observational research. The survey consisted of open-ended and Likert scale questions as well as basic demographic information. The questionnaire was piloted with the parents of three hospitalized children. Minor adjustments were made in response in order to clarify items. Responses were recorded verbatim by the surveyor. Subjects were recruited using convenience sampling in the pediatric intensive care unit (PICU) and in the pediatric wards between November 5, 2014 and April 8,2016 . Surveying was scheduled to include different times of day and weekend days. Parents were not approached if the treating physician or bedside nurse felt that the child's condition was too unstable or that the parents were too upset to be approached for research participation. Participants provided verbal consent to participate in this study.

Six different versions of the handout were used. The generic version of the handout (Figure 1A) described observational research in general, without details about any specific study. The remaining five handouts each briefly described a specific study (Figure 1B). Four of these studyspecific handouts related to a specific disease condition (asthma, cardiac disease, cancer, or seizure disorders) and one related to antibiotic use. All described the same study design, which entailed observing a child's heart rate before and after administration of a medication that the child would receive as part of routine clinical care. Survey participants were only given a study-specific handout if their child could be eligible to participate in the specific hypothetical study described in that handout.

Categorical data were compared using two-tailed chi-square analysis as appropriate. Qualitative data were evaluated using thematic analysis. Content analysis of the responses of open-ended questions was performed by all investigators to identify recurring themes. Together, the investigators then developed a definition for each theme. Each response was independently coded according to these definitions both by the senior author and by at least one coinvestigator. Discrepancies were resolved to the satisfaction of all. The study was approved by the Columbia University Medical Center Institutional Review Board.

\section{Results}

A total of 166 participants completed the survey between November 5, 2014 and April 8, 2016. Subject characteristics are shown in Table 1.

After parents reviewed the handout, they were asked: "Could you please tell me in your own words what this handout says?" A total of 50/166 parents (30\%) replied with a simple description of the research, $48 / 166$ parents $(30 \%)$ made statements that were positive about medical research, 


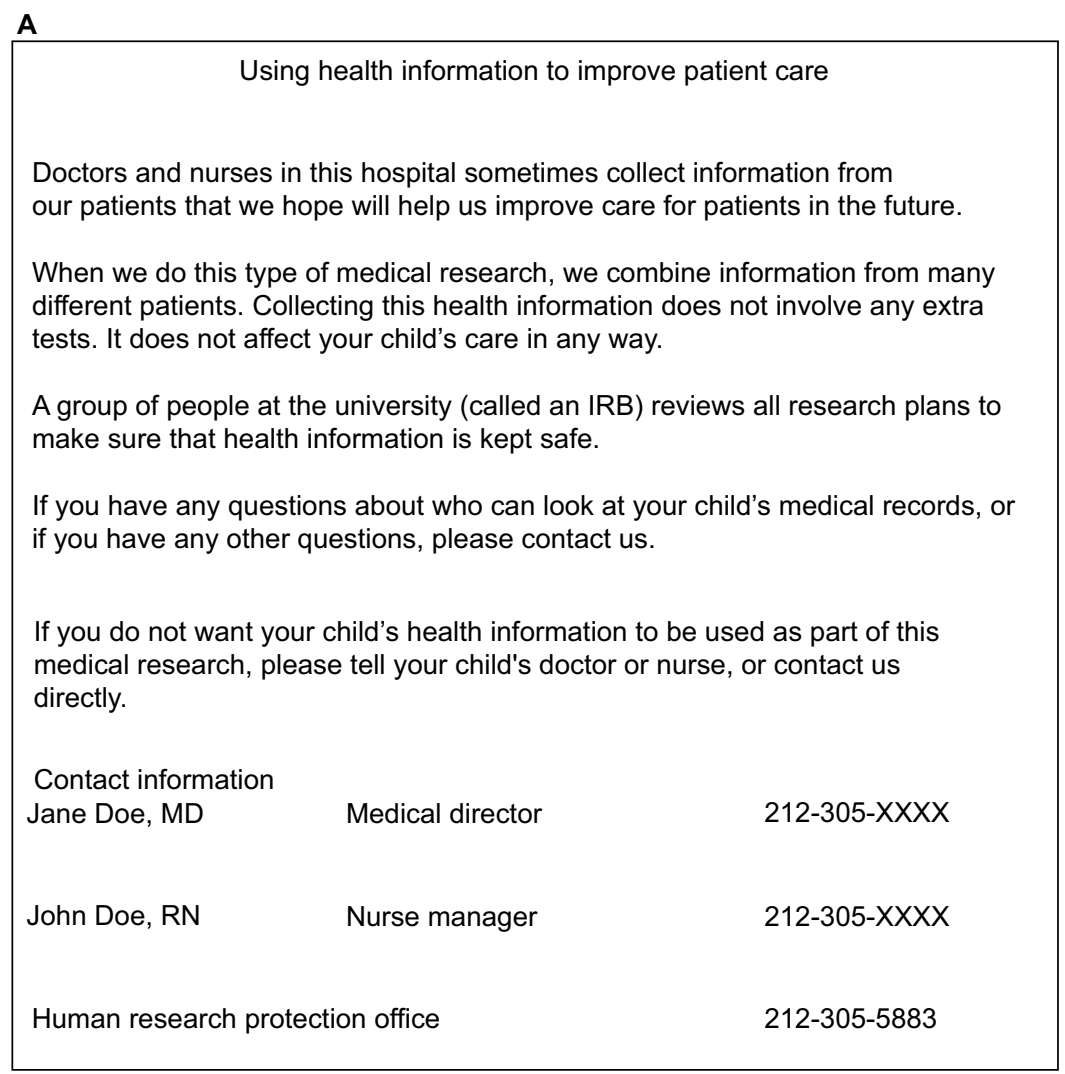

B

Using health information to improve cardiac care

Doctors in this hospital are trying to learn how certain heart medications affect children's heart rate. We would like to look at the medical record of children admitted with heart disease to see what medications they are receiving. We will look at the child's monitor or nursing record and record each child's heart rate before and after medications. We hope that this information will help us improve care for patients in the future.

Figure I Sample handouts. The shown information was printed on hospital letterhead, with the words "FOR DEMONSTRATION PURPOSES ONLY" written across the top. (A) Generic handout. (B) For study-specific handouts, the title and the first paragraph of the generic handout were replaced with study-specific language. The remainder of the handout was the same as the generic handout.

Abbreviation: IRB, institutional review board.

$21 / 166(13 \%)$ commented that the research described would not impact the child, and $14 / 166$ parents (8.4\%) specifically noted the need to opt-out if they did not want their child to participate. Eight parents referenced "permission" or "consent" without clearly indicating understanding of the opt-out requirement (e.g. "Giving you permission to look at his records" and "That you're asking our permission to look at his medical records"). A total of $16 / 166$ parents $(9.6 \%)$ gave a response suggesting that they had not understood or had misunderstood the content of the handout. Two parents implied objections, one stating, "I'd have to go out of my way to tell the nurse I don't want to" and the other, "You are performing research on my child as we speak and apparently no one told me".

Parents were then asked: "What is your first reaction upon reading this handout?" A total of $75 / 166$ parents (45\%) made a comment that was positive about research in general, 12 $(7.2 \%)$ mentioned that the research did not impact the child, $10(6.0 \%)$ expressed concern about privacy, 9 (5.4\%) made statements indicating misunderstanding of the handout, and 6 $(3.6 \%)$ said that they would want more information. Two parents (1\%) expressed anger ("Angry that information about my son is being collected and no one bothered to tell me" and "My child is not a guinea pig"). One parent said she would opt-out. 
Table I Study participants

\begin{tabular}{|c|c|c|}
\hline Category & $\begin{array}{l}\text { Study-specific } \\
\text { handout }(n=103)\end{array}$ & $\begin{array}{l}\text { Generic research } \\
\text { handout }(n=63)\end{array}$ \\
\hline \multicolumn{3}{|l|}{ Sex of patient, n (\%) } \\
\hline Male & $58(56)$ & $33(52)$ \\
\hline Female & $45(44)$ & $30(48)$ \\
\hline \multicolumn{3}{|l|}{ Age of patient, $n(\%)$} \\
\hline$<$ l yo & $25(24)$ & $16(25)$ \\
\hline $1-5$ yо & $38(37)$ & $20(32)$ \\
\hline $6-12$ yo & $21(20)$ & $13(21)$ \\
\hline $13-17$ yo & $19(18)$ & $11(18)$ \\
\hline 18 yo+ & $0(0)$ & $3(5)$ \\
\hline \multicolumn{3}{|l|}{ Admission location, $n(\%)$} \\
\hline PICU & $46(45)$ & $36(57)$ \\
\hline Pediatric ward & $57(55)$ & $27(43)$ \\
\hline \multicolumn{3}{|l|}{ Participant, n (\%) } \\
\hline Mother & $87(84)$ & $5 I(8 I)$ \\
\hline Father & $15(15)$ & II (I8) \\
\hline Other legal guardian & $\mathrm{I}(\mathrm{I})$ & I (2) \\
\hline \multicolumn{3}{|c|}{ Self-reported ethnicity of participant, n (\%) } \\
\hline White & $26(25)$ & $22(35)$ \\
\hline Hispanic & $35(34)$ & $20(32)$ \\
\hline Black & $14(14)$ & $8(13)$ \\
\hline Asian & $6(6)$ & $2(3)$ \\
\hline Other & $17(17)$ & $9(14)$ \\
\hline No response & $5(5)$ & $2(3)$ \\
\hline \multicolumn{3}{|c|}{ Education of participant, n (\%) } \\
\hline Did not complete HS & $7(7)$ & $4(6)$ \\
\hline GED or high school & $18(18)$ & $14(22)$ \\
\hline $\begin{array}{l}\text { Some college or } \\
\text { associates degree }\end{array}$ & $36(35)$ & $19(30)$ \\
\hline Bachelor's degree & $25(24)$ & II (I8) \\
\hline $\begin{array}{l}\text { Other professional } \\
\text { degree }\end{array}$ & $16(16)$ & $15(24)$ \\
\hline No response & $I(I)$ & $0(0)$ \\
\hline \multicolumn{3}{|c|}{ Child's hospitalizations, n (\%) } \\
\hline Ist hospitalization & $24(23)$ & $24(38)$ \\
\hline $\begin{array}{l}\text { I-2 previous } \\
\text { hospitalizations }\end{array}$ & $16(16)$ & $9(14)$ \\
\hline $\begin{array}{l}3+\text { previous } \\
\text { hospitalizations }\end{array}$ & $63(61)$ & $30(48)$ \\
\hline \multicolumn{3}{|l|}{ Handout version, n (\%) } \\
\hline Generic & & 63 \\
\hline \multicolumn{3}{|l|}{ Study-specific } \\
\hline Antibiotics & $33(32)$ & \\
\hline Asthma & $15(15)$ & \\
\hline Cardiac disease & $28(27)$ & \\
\hline Cancer & $16(16)$ & \\
\hline Seizures & II (II) & \\
\hline
\end{tabular}

Abbreviations: yo, years old; PICU, pediatric intensive care unit; $\mathrm{HS}$, high school; GED, graduate equivalent degree.

Each parent was asked: "Is it okay to tell you about this kind of research using this handout?" This question was added to the survey after the first nine surveys were completed; therefore, $n=157$. A total of $116 / 157$ parents $(74 \%)$ responded positively ("I assume this is done anyway to track data. I think a handout is fine"), 19/157 (12\%) responded negatively ("No, it should always be a conversation"), and 21/157 (13\%) made an indeterminate response ("I would like to know a little bit more information on the research itself"). One parent did not answer the question (Figure 2). There was no statistically significant difference in responses to this question between parents of children admitted to the PICU and parents of children admitted to a pediatric ward, or between parents who received a generic handout and those who received a disease-specific handout.

Participants were then given examples of prospective observational research and were asked: "Do you think that doctors and nurses in this hospital should do this kind of research?" Responses were as follows: definitely yes, $138 / 166$ (83\%); probably yes, $24 / 166(14 \%)$; probably no, $3 / 166$ (2\%); and definitely no, $1 / 166(0.6 \%)$. There were no statistically significant differences in responses between parents of children admitted to the PICU and parents of children admitted to a pediatric ward, or between parents who received a generic handout and those who received a disease-specific handout.

After a brief discussion of the pros and cons of an optout process, parents were asked to indicate which consent approach they would choose for future prospective observational research in children: 1) researcher should be required to speak with each parent and get permission in addition to giving the handout (opt-in); 2) researcher should distribute handout without speaking to each parent individually (optout); or 3) no handout or discussion is needed (no consent needed). Of the 166 parents, 86 (52\%) chose opt-in, 54 (33\%) chose opt-out, and 25 (15\%) chose no consent needed. One participant did not pick any of the available options; she stated that the researcher should not be required to speak with guardians, but that a parental signature should be obtained (Figure 3).

Parents who identified themselves as White and parents with a higher level of education were more likely to endorse an opt-out or no-consent approach to minimal risk, observational research (41/79 [62\% of those with a bachelor's degree or higher] vs. 38/68 [39\% of those with an associate's degree or less], $p<0.01$; Table 2 ). We found no statistically significant associations between parents' preferred consent method and the admission location (PICU vs. pediatric ward), type of handout reviewed (generic vs. study-specific or diseasespecific vs. the antibiotic study), or the child's total number of hospitalizations (Table 2).

All qualitative responses and comments participants made over the course of the survey were categorized according to theme (Table 3). A total of 134 parents (81\%) made comments 


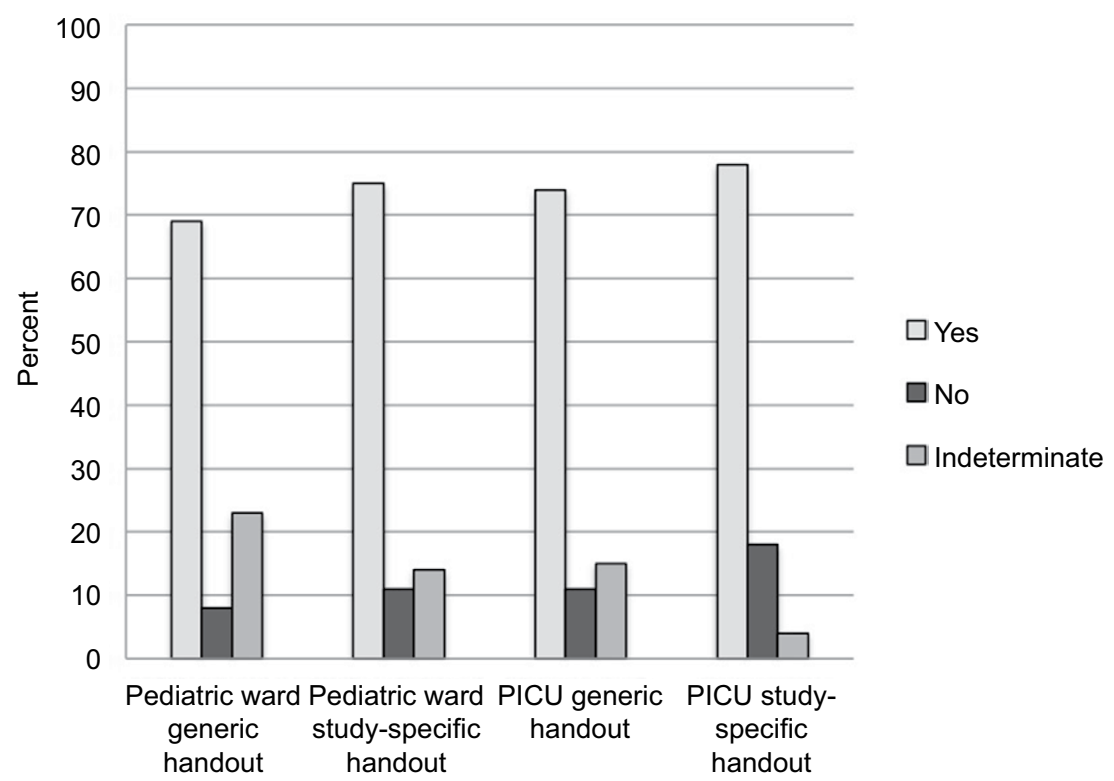

Figure 2 Parental responses to question "Is it ok to tell you about this kind of research using this handout?" Abbreviation: $\mathrm{PICU}$, pediatric intensive care unit.

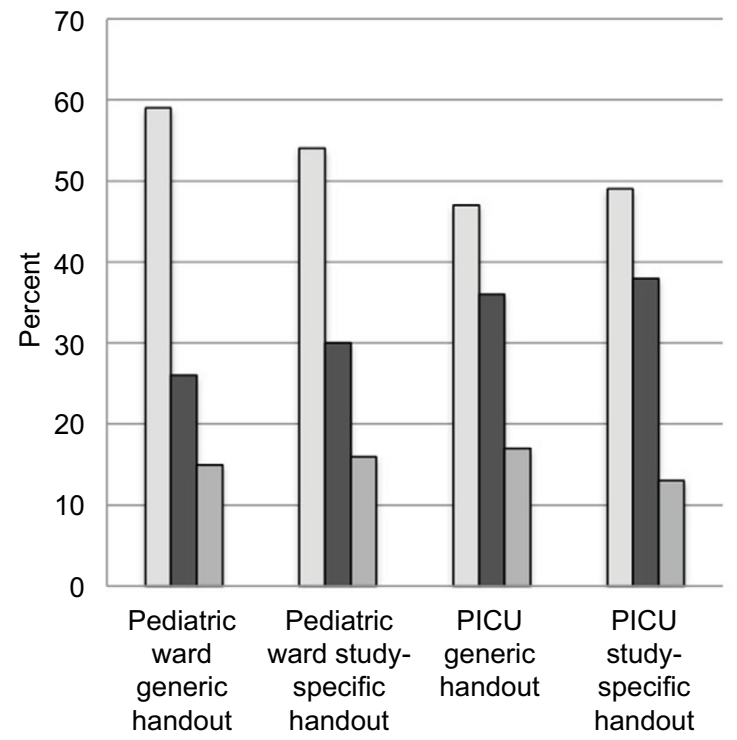

$\square$ Researcher and handout (opt-in)

$\square$ Handout only (optout)

$\square$ No need to seek consent

Figure 3 Parental responses when asked which approach they prefer for prospective observational research (one parent who did not choose among the available options has been excluded).

Abbreviation: PICU, pediatric intensive care unit.

that were positive about the research described and $5(3 \%)$ made comments that were negative. Sixty patients $(36 \%)$ specifically mentioned that the research would not impact their children, 22 (13\%) parents expressed misunderstanding of the hypothetical studies at some point during the survey, and $22(13 \%)$ parents commented that the handout should contain more information. There were no significant differences between the thematic coding of comments made by parents who reviewed the generic handout and those made by parents who reviewed a study-specific handout.

\section{Discussion}

In this study, we sought to learn how parents would respond to an opt-out consent process for prospective observational research involving hospitalized children. We approached the question from three different angles: 1) How do parents describe their initial reactions after reviewing opt-out handout? 2) Do parents endorse the an opt-out process when the alternative of an opt-in process is not discussed? 3) What selection do parents make when asked to choose between an opt-out consent, an opt-in consent, and no consent for future observational research. 
Table 2 Associations between parental or child factors and consent preferences (one parent who did not choose among the available options has been excluded)

\begin{tabular}{|c|c|c|c|}
\hline Category & $\begin{array}{l}\text { Chose opt-out } \\
\text { or no consent } \\
(n=79)\end{array}$ & $\begin{array}{l}\text { Chose opt-in } \\
\text { consent } \\
(n=86)\end{array}$ & $p$-Value \\
\hline \multicolumn{4}{|c|}{ Child's number of hospitalizations, $n(\%)$} \\
\hline First hospitalization & $22(46)$ & $25(53)$ & \\
\hline $\begin{array}{l}\text { At least one prior } \\
\text { hospitalization }\end{array}$ & $57(48)$ & $61(52)$ & 0.89 \\
\hline \multicolumn{4}{|c|}{ Parental education level, n (\%) } \\
\hline $\begin{array}{l}\text { Bachelor's degree or } \\
\text { higher }\end{array}$ & $4 \mid(62)$ & $25(38)$ & \\
\hline $\begin{array}{l}\text { Associate's degree or } \\
\text { less }\end{array}$ & $38(39)$ & $60(6 \mathrm{I})$ & \\
\hline Did not respond & $0(0)$ & $I(I)$ & $<0.01$ \\
\hline \multicolumn{4}{|c|}{ Self-described ethnicity, n (\%) } \\
\hline White & $34(72)$ & $13(28)$ & \\
\hline Hispanic & $24(44)$ & $31(56)$ & \\
\hline Black & $5(23)$ & $17(74)$ & \\
\hline Other & $16(39)$ & $25(61)$ & $<0.01$ \\
\hline
\end{tabular}

In order to assess the reactions that opt-out handouts might provoke in a real-world setting, handouts describing hypothetical research studies were distributed with minimal explanation, and parents were asked: "What is your first reaction upon reading this handout?" The most frequent responses indicated support of medical research. Parents also commonly mentioned the fact that research participation would not affect their children. The primary objections mentioned were concern about privacy of medical records and a desire for more information than the handout contained. These concerns suggest ways to improve an opt-out information sheet, perhaps by including a statement describing privacy protections and including bulleted information points on the reverse side of a handout. We suggest that the reverse side of a handout should describe the study in more depth, including privacy protections and a list of the specific information that will be collected. Additionally, we believe the handout could be improved by including a prominent statement along the lines of: "The people who are doing this research would be happy to speak with you if you have any questions or would like more information. If you would like to speak with a researcher, please ask your child's nurse or doctor."

Two parents made comments indicating that an opt-out consent process would make them angry or upset ("[I'd be] angry that information about my son is being collected and no one bothered to tell me" and "My child is not a guinea pig"). Though the absolute number of parents voicing this type of response was small, the statements highlight the importance of ensuring that parents know that investigators are readily available to talk about any concerns that they may have.

Table 3 Themes noted in parental comments

\begin{tabular}{|c|c|c|}
\hline Theme & $\mathbf{N}(\%)$ & Representative quote \\
\hline Positive about research in general & $134(81)$ & I'm actually happy that you guys are doing research on this to help future patients. \\
\hline $\begin{array}{l}\text { The research will not impact the } \\
\text { child }\end{array}$ & $60(36)$ & $\begin{array}{l}\text { If it doesn't hurt him, then I don't mind. Don't see any negative side effects of doing this. } \\
\text { It won't affect the healthcare of my child. It's just to advance medicine. }\end{array}$ \\
\hline Concern about privacy & $33(20)$ & $\begin{array}{l}\text { I first thought...did someone try to look at his medical records? I feel like I should be } \\
\text { the only one looking at his medical records besides insurance and the primary doctors. } \\
\text { Unless they get my permission, no one has the right to collect my son's health } \\
\text { information. }\end{array}$ \\
\hline $\begin{array}{l}\text { Parents want more information } \\
\text { than the handout contains }\end{array}$ & $22(13)$ & $\begin{array}{l}\text { I don't know if it gives a lot of information about what the study is. Parents might have } \\
\text { follow up questions. }\end{array}$ \\
\hline $\begin{array}{l}\text { Statements indicating parent did } \\
\text { not understand or misunderstood } \\
\text { something in the handout }\end{array}$ & $22(13)$ & $\begin{array}{l}\text { It's confusing. I wouldn't understand what it means. } \\
\text { It's about them taking care of patients-running tests to make sure they're okay before } \\
\text { they go home. [Response to "can you tell me in your own words what this handout } \\
\text { says"]. }\end{array}$ \\
\hline $\begin{array}{l}\text { Benefits to handout over face-to- } \\
\text { face discussion }\end{array}$ & $18(\mathrm{II})$ & $\begin{array}{l}\text { [Benefit to parents, } n=7] \text {. Sometimes it's annoying-it's annoying for researchers to } \\
\text { come by when you're worried about your sick child. Just do it with a handout. } \\
\text { [Benefits to researchers, } n=7] \text {. To find each individual parent to get consent... with } \\
\text { research time is of the essence. It would cut down on time if you just give a handout. } \\
\text { [Non-specific benefits, } n=4] \text {. It's more efficient if you just read this. }\end{array}$ \\
\hline Some people might not read it & $18(1 \mathrm{I})$ & Should have to sign so that you know they read it. Otherwise parents won't. \\
\hline $\begin{array}{l}\text { Research is done as a matter of } \\
\text { course at a university hospital }\end{array}$ & $16(10)$ & It's a teaching hospital and comes with the territory. \\
\hline $\begin{array}{l}\text { Research might negatively affect } \\
\text { the child }\end{array}$ & $5(3)$ & I don't want my child's care affected by research. \\
\hline
\end{tabular}

$\mathrm{N}=$ number of parents who made at least one comment during the survey that was categorized according to the theme. 
Researchers should be sure that nurses and doctors caring for the child are familiar with the study and are ready to answer parental questions and to put parents in touch with investigators.

After parents' initial reactions were ascertained, the surveyor answered any questions they had about the handout, and then parents were asked: "Is it ok to tell you about this research using this handout?" The question intentionally omitted mention of an alternative, as the intent was primarily to determine in a very general sense what proportion of parents might be upset if they received a similar handout. We found that $12 \%$ of parents responded negatively to that question. An additional 13\% made neutral or indeterminate responses. These findings reinforce published data indicating that, in practice, patients and their families are accepting of opt-out consent processes for observational research. ${ }^{8-10}$

While few parents cited objections to the opt-out process when it was described in isolation, when given a side-by-side choice, $52 \%$ voiced a preference for an opt-in approach for observational research involving hospitalized children. It is informative to compare our findings to another survey, in which only $31 \%$ of respondents agreed that retrospective medical record research should proceed without consent; $14 \%$ were neutral and 55\% disagreed. ${ }^{14}$ It is also challenging to determine what role the general public opinion should play in deciding what form of consent is needed for minimal risk studies such as observational research. The bioethicist Franklin Miller cautions that while survey responses of the general public ought not be ignored, they also ought not be considered determinative of best practices. ${ }^{15}$ In our sample, $11 \%$ of participants cited a specific advantage of an opt-out process and $10 \%$ of participants noted their impression that research is a routine part of being admitted to an academic medical center.

We found no significant difference in the opinions of parents of children admitted to the PICU compared to parents of children admitted to the pediatric wards. However, we did not approach parents of PICU patients if the nurse or treating physician felt that the parents were upset or that the child was acutely unstable. The potential for selection bias introduced by an opt-in consent approach may be exaggerated in the PICU setting, as parents are either not approached or are unwilling to consider research participation due to more stressful conditions. ${ }^{16}$

We found more acceptance of an opt-out approach among parents who self-identified as White and among parents with a higher level of education. The associations between demographic factors such as race or educational level and research participation are complex and incompletely understood. ${ }^{17}$ Our findings align with research indicating that mistrust of the medical research community is greater in minority populations in the US. ${ }^{18,19}$ A 2003 study by Kass et al showed that participants with annual incomes less than $\$ 20,000$ were twice as likely to agree that researchers should use records for research without permission. ${ }^{14}$ To the extent that income serves as a proxy for level of education, our results do not align with this finding.

\section{Limitations}

Our study has several important limitations. Foremost, it is unclear to what extent our findings can be extrapolated to countries other than the US, as regulations differ. Further, we used convenience sampling and we enrolled English-speaking parents only. We also excluded parents of patients who were acutely unstable and any other parents if the nurse or doctor felt that the parent should not be disturbed. Our study is also limited by the fact that parental responses to a hypothetical study may not perfectly reflect reactions to a real study. Further work is needed to evaluate parental responses when an opt-out mechanism is used in a real inpatient pediatric observational research study.

\section{Conclusion}

Parents' reactions to reviewing our handout suggest they would be accepting of an opt-out consent process for prospective observational research in the inpatient pediatric setting. However, when asked to choose between an opt-in and an opt-out process, approximately half said they would prefer an opt-in process. Together, these data suggest that investigators and IRBs wishing to use this approach should proceed cautiously. We support using a handout as an opt-out mechanism for inpatient pediatric research only when mechanisms are in place to ensure that parental concerns and questions can be promptly addressed. Parents should know that investigators are readily available if they have questions or concerns about the research. Opt-out materials should include a prominently placed statement such as: "The people who are doing this research would be happy to speak with you if you have any questions or would like more information. If you would like to speak with a researcher, please ask your child's nurse or doctor".

\section{Disclosure}

The authors report no conflicts of interest in this work.

\section{References}

1. Code of Federal Regulations. 45 CFR 46.116-General Requirements for Informed Consent. Available from: https:/www.hhs.gov/ohrp/ regulations-and-policy/regulations/45-cfr-46/. Accessed January 4, 2017.

2. Yawn BP, Yawn RA, Geier GR, Xia Z, Jacobsen SJ. The impact of requiring patient authorization for use of data in medical records research. J Fam Pract. 1998;47(5):361-365.

3. Jacobsen SJ, Xia Z, Campion ME, et al. Potential effect of authorization bias on medical record research. Mayo Clin Proc. 1999;74(4):330-338. 
4. Woolf SH, Rothemich SF, Johnson RE, Marsland DW. Selection bias from requiring patients to give consent to examine data for health services research. Arch Fam Med. 2000;9(10):1111-1118.

5. Tu JV, Willison DJ, Silver FL, et al; Investigators in the Registry of the Canadian Stroke Network. Impracticability of informed consent in the Registry of the Canadian Stroke Network. NEngl J Med. 2004;350(14): 1414-1421.

6. Buckley B, Murphy AW, Byrne M, Glynn L. Selection bias resulting from the requirement for prior consent in observational research: a community cohort of people with ischaemic heart disease. Heart. 2007; 93(9):1116-1120.

7. SACHRP. January 10, 2013 SACHRP Letter to the HHS Secretary; Attachment D: Informed Consent and Waiver of Consent. SACHRP; 2013. Available from: https://www.hhs.gov/ohrp/sachrp-committee/ recommendations/2013-january-10-letter/index.html. Accessed January 4, 2017.

8. Junghans C, Feder G, Hemingway H, Timmis A, Jones M. Recruiting patients to medical research: double blind randomised trial of "opt-in" versus “opt-out” strategies. BMJ. 2005;331(7522):940.

9. Berry JG, Ryan P, Gold MS, Braunack-Mayer AJ, Duszynski KM; Vaccine Assessment Using Linked Data (VALiD) Working Group. A randomised controlled trial to compare opt-in and opt-out parental consent for childhood vaccine safety surveillance using data linkage. J Med Ethics. 2012;38(10):619-625.

10. Higgerson RA, Olsho LE, Christie LM, et al; PALISI PICFlu Study Investigators. Variability in IRBs regarding parental acceptance of passive consent. Pediatrics. 2014;134(2):e496-e503.
11. Damschroder LJ, Pritts JL, Neblo MA, Kalarickal RJ, Creswell JW, Hayward RA. Patients, privacy, and trust: patients' willingness to allow researchers to access their medical records. Soc Sci Med. 2007;64(1):223-235.

12. Brothers KB, Westbrook MJ, Wright MF, et al. Patient awareness and approval for an opt-out genomic biorepository. Per Med. 2013; 10(4):349-359.

13. Stevenson F, Lloyd N, Harrington L, Wallace P. Use of electronic patient records for research: views of patients and staff in general practice. Fam Pract. 2013;30(2):227-232.

14. Kass NE, Natowicz MR, Hull SC, et al. The use of medical records in research: what do patients want? J Law Med Ethics. 2003;31(3): 429-433.

15. Miller FJ. The Ethical Challenges of Human Research: Selected Essays. Oxford: Oxford University Press; 2012.

16. Menon K, Ward R; Canadian Critical Care Trials Group. A study of consent for participation in a non-therapeutic study in the pediatric intensive care population. J Med Ethics. 2014;40(2):123-126.

17. Fisher JA, Kalbaugh CA. Challenging assumptions about minority participation in US clinical research. Am J Public Health. 2011:101(12): 2217-2222.

18. Corbie-Smith G, Thomas SB, St George DM. Distrust, race, and research. Arch Intern Med. 2002;162(21):2458-2463.

19. Braunstein JB, Sherber NS, Schulman SP, Ding EL, Powe NR. Race, medical researcher distrust, perceived harm, and willingness to participate in cardiovascular prevention trials. Medicine (Baltimore). 2008; 87(1):1-9.
Pragmatic and Observational Research

\section{Publish your work in this journal}

Pragmatic and Observational Research is an international, peer-reviewed, open access journal that publishes data from studies designed to reflect more closely medical interventions in real-world clinical practice compared with classical randomized controlled trials (RCTs). The manuscript management system is completely online and includes a very quick and fair peer-review

\section{Dovepress}

system. Visit http://www.dovepress.com/testimonials.php to read real quotes from published authors. 